\title{
A Novel PID Control Strategy Based on Improved GA-BP Neural Network for Phase-Shifted Full-Bridge Current-Doubler Synchronous Rectifying Converter
}

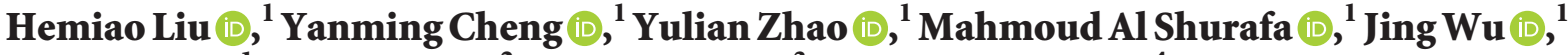 \\ Cheng Liu $\left(\mathbb{1},{ }^{1}\right.$ Ilkyoo Lee $\left(\mathbb{1},{ }^{2}\right.$ Minwoo Lee $\left(\mathbb{1},{ }^{3}\right.$ and Jaesang Cha $\mathbb{C}^{4}$ \\ ${ }^{1}$ College of Electrical and Information Engineering, Beihua University, Jilin, China \\ ${ }^{2}$ Department of Electrical, Electronics \& Control Engineering Kongju National University, Cheonan, Republic of Korea \\ ${ }^{3}$ IT Convergence Technology Research Lab, Seoul National University of Science and Technology, Seoul, Republic of Korea \\ ${ }^{4}$ Department of Electronics and IT Media Engineering, Seoul National University of Science and Technology, \\ Seoul, Republic of Korea \\ Correspondence should be addressed to Yanming Cheng; mycheng@kongju.ac.kr
}

Received 15 December 2020; Revised 26 February 2021; Accepted 12 March 2021; Published 26 March 2021

Academic Editor: Zhiwen Chen

Copyright (C) 2021 Hemiao Liu et al. This is an open access article distributed under the Creative Commons Attribution License, which permits unrestricted use, distribution, and reproduction in any medium, provided the original work is properly cited.

In this paper, a phase-shifted full-bridge current-doubler synchronous rectifying converter (PSFB-CDSRC) based on IGBT and its control strategies are studied. In the main circuit, a current doubling synchronous rectifying circuit based on IGBT is presented to further reduce the power loss of power devices. Moreover, in the control strategy, in view of the existing researches, the basic BP neural network PID control performance of the rectifying converter still can be further improved. Therefore, this paper combines the quasi-Newton algorithm and traditional GA to propose an improved GA-BP (IGA-BP) neural network to further improve PID control performance. The simulation results demonstrate that the maximum efficiency of $5 \mathrm{~V} / 500 \mathrm{~A}$ rectifying converter based on the proposed circuit scheme can reach $94.1 \%$, and the rectifying converter has a good performance of excellent waveform and wide range of load. IGA-BP neural network PID control responds fast and reaches the stable state quickly in comparison with that controlled by the GA-BP neural network control strategy, and the steady-state time can be reduced by $10.5 \%$ through using IGA-BP neural network control strategy. This study can provide a valuable guidance and reference, not only in circuit scheme but also in the optimal PID control strategy for design of the high-efficiency DC/DC rectifying converter with higher power in the future.

\section{Introduction}

The full-bridge DC/DC converter has been widely applied in high power DC/DC converters owing to its higher utilization and flexible control methods. Zero Voltage Switch (ZVS) is chosen as the common control method which does not need auxiliary switch, but there is a serious problem of duty cycle loss in the secondary. Literature $[1,2]$ analyzed the working process of the phase-shifted fullbridge ZVS DC/DC converter with isolating capacitance, focused on the influence of isolating capacitance on the performance of the converter, and described the detail of the principle of compensating the duty cycle loss through reasonable allocation between isolating capacitance and leakage inductance of transformer. However, the mentioned method reduces the ZVS range of the lagging arm and increases the voltage stress of the rectifying diode. In the applications of low voltage and high current of the rectifier, the improvement of power efficiency is limited by the power loss generated by the forward voltage drop of the rectifying diode. Literatures [3-5] presented IGBT to replace MOSFET in main circuit to reduce power loss. Literature studies $[6,7]$ used the double-current synchronous rectifying technology on the secondary side of the 
transformer, and combined the current-doubler rectifying technology with the synchronous rectifying technology, which not only realized the ZVS of the full-bridge switching transistor, but also improved the insufficient soft switch of the secondary synchronous rectifying, and improved the current ripple by doubling the current. In literatures $[8,9]$, IGBT is used in phase-shifting full-bridge circuit and MOSFET is used in secondary side synchronous rectifying circuit of transformer. The power loss of main circuit and each switching state of switch tube are analyzed in detail. However, in exiting researches, only MOSFET was taken into account to be used to achieve double-current synchronous. Based on the above analysis, this paper proposes a high efficiency phase-shifted full-bridge circuit of the DC/ DC rectifying converter consisting of high frequency IGBT, and a current doubling synchronous rectifier consisting of IGBT in side of the transformer secondary.

However, one of the challenges facing a rectifying converter system is the large inertia and time-varying uncertainty of the controlled object. In recent years, scholars have proposed some intelligent PID, including expert PID, fuzzy PID, neural network PID, BP neural network PID, and so on. Each control method has its own advantages and limitations. For example, the expert PID control is based on the experience of its expert knowledge base. If the experience value is unreasonable, the expected control effect cannot be achieved [10]. Fuzzy control has strong fault tolerance, but fuzzy processing will reduce the control accuracy and dynamic quality of the system [11]. In literature $[12,13]$, neural network PID has the ability of online estimation and self-learning and can be approximated by any nonlinearity. Moreover, the regulation process does not depend on the system model, which is suitable for the control of rectifying converter. Literature $[13,14]$ presented a BP neural network with double learning rate for PID controller in phase-shifted full bridge softswitching power supply. But the inherent shortcomings of common neural networks are slow convergence speed and easy to fall into local optimum. It is obvious that the existing researches only did study on the basic BP neural network to improve the PID control performance in phase-shifted fullbridge rectifying converter. Therefore, In PID control strategy of DC/DC rectifying converter, this paper proposes an efficient genetic algorithm BP (GA-BP) neural network to improve PID control for phase-shift full-bridge current-doubler synchronous rectifying converter, for further improving the PID control performance in phase-shift full-bridge currentdoubler synchronous rectifying converter. Some candidate evolutionary algorithms [15-17] for improving GA-BP neural network are as follows: gradient descent that has the convergence rate slows down near the minimum. Newton's method is an iterative algorithm, each step needs to solve the inverse matrix of Hessian matrix of the objective function, and the calculation is more complex. It has second-order convergence. Quasi-Newton methods do not need the information of second derivative; they are more effective than Newton method. Conjugate gradient is a method between steepest descent method and Newton method; it is more suitable for solving large linear and nonlinear equations.
Therefore, the quasi-Newton algorithm is selected to improve genetic algorithm BP (IGA-BP) neural network. Through conducting modelling and simulation in MATLAB, the effectiveness, rapidity, stability, accuracy, and robustness of IGA-BP neural network as the optimal PID control strategy are verified.

\section{Circuit System Design}

2.1. Phase-Shift Full-Bridge Current-Doubler Synchronous Rectifying Converter. For decreasing power loss of power devices, reducing ripple factor of output current, in this paper, a topology of phase-shift full-bridge current-doubler synchronous rectifying converter (PSFB-CDSRC) is illustrated in Figure 1. The main circuit is used on the primary side of the transformer, and a current-doubler synchronous rectifier is used on the secondary of the transformer. The main circuit consists of four switch transistors $Q_{1} \sim Q_{4}$, a resonant inductor $L_{r}$, an isolation capacitor $C_{b}$, a transformer $T$, and two clamping diodes $D_{7}$ and $D_{8} . C_{1} \sim C_{4}$ and $D_{1} \sim D_{4}$ are the junction capacitance and reverse parallel diodes of $Q_{1} \sim Q_{4}$, respectively. The circuit of the transformer secondary consists of synchronous rectifiers $Q_{5}$ and $Q_{6}$, filter inductors $L_{f 1}$ and $L_{f 2}$, and output filter capacitance $C_{f}$. In phase-shifting control, the forward arm consists of $Q_{1}$ and $Q_{2}$, and the lag arm consists of $Q_{3}$ and $Q_{4}$.

2.2. Design of Closed-Loop Control System. For the double closed-loop control system, in the general design procedure, firstly, the current inner loop is designed. Secondly, the closed-loop transfer function of the current inner loop is taken as a part of the voltage loop, and then the outer voltage loop is designed.

The control block diagram of the current inner loop is shown in Figure 2. $G_{i c}(s)$ is the compensation element of the current loop. The output current $i_{0}$ passes through the current loop gain $K_{i}$ as the feedback signal and then passes through the error amplifier and compensates to generate the error signal $V_{e}$. The pulse width signal is generated by the module $K_{\mathrm{PWM}}$, which depends on the size of $V_{e}$. The signal can adjust the output voltage by changing the switching rate of the driving circuit.

Closed loop transfer function of current inner loop can be written as

$$
G_{i}(s)=\frac{G_{\mathrm{ic}}(s) G_{\mathrm{id}}(s) K_{i} K_{\mathrm{PWM}}}{1+G_{\mathrm{ic}}(s) G_{\mathrm{id}}(s) K_{i} K_{\mathrm{PWM}}} .
$$

According to the transfer function of the inner current loop, the output current value is independent of the current compensation network, only depending on the current given value and the current sampling value. Therefore, the current loop can be equivalent to a proportional part of the voltage loop.

In practical circuits, the current closed-loop transfer function can be further equivalent as

$$
G_{i}(s)=\frac{1}{k_{i}} .
$$




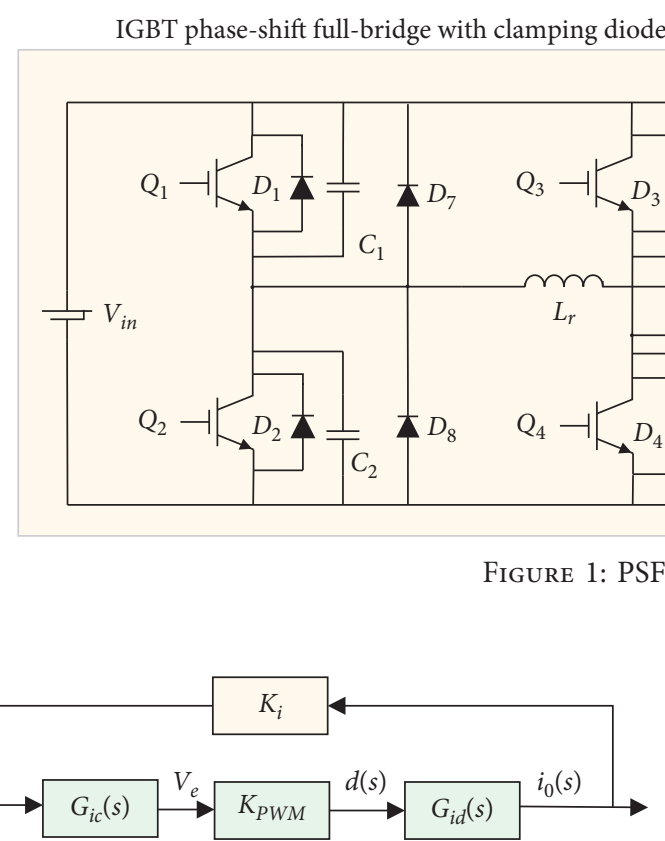

FIGURE 2: Block diagram of current loop control transfer function.

The inner voltage loop control block diagram with equivalent current closed-loop transfer function is illustrated in Figure 3. $G_{\mathrm{vd}}(s)$ is the transfer function of duty ratio $d(s)$ of PSFB-CDSRC to output $V_{0}(s), G_{i}(s)$ is $t$ the current closed-loop transfer function, $K_{v}(s)$ is the transfer function of feedback network, and $G_{\mathrm{vc}}(s)$ is the transfer function of compensation network of voltage loop.

The transfer function after compensation is written as

$$
G(s)=G_{\mathrm{vc}}(s) G_{i}(s) G_{\mathrm{vd}}(s) K_{v}(s) .
$$

By substituting $G_{\mathrm{vd}}(s)=\left(v_{0}(s) / d(s)\right)=\left(\left(V_{\text {in }} / n\right) / 0.5 L_{f}\right.$ $\left.C_{f} s^{2}+\left(0.5 C_{f} R_{\mathrm{eq}}+\left(L / R_{L}\right)\right) s+\left(R_{\mathrm{eq}} / 2 L\right)+1\right), \quad K_{v}(s)=1$, $G_{i}(s)=\left(1 / K_{i}\right)=10^{3}, L_{f}=1 \mu \mathrm{H}, C_{f}=0.5 \mathrm{mF}, R_{\mathrm{eq}}=\left(2 L_{r}\right.$ $\left.f_{s} / n^{2}\right), R_{L}=0.01 \Omega$ the parameters of the system into equation (3), $G(s)$ is obtained as

$$
G(s)=\frac{12 \times 10^{3}}{2.5 \times 10^{-8} s^{2}+5.025 \times 10^{-4} s+1.05} G_{\mathrm{vc}}(s) .
$$

The transfer function of controller compensation $G_{\mathrm{vc}}(s)$ is obtained as

$$
G_{\mathrm{vc}}(s)=1.3059 \times \frac{1+0.00014 s}{s} .
$$

The Bode diagram of the system after correction can be obtained in Figure 4. The phase margin of the system is 22 $\mathrm{deg}$, and the crossing frequency $W_{c}$ is $6.48 \mathrm{kHz}$, which meets the requirements of stability for the system.

\section{Design of BP Neural Network PID Control Based on Improved GA}

3.1. BP Neural Network PID Controller. BP neural network PID is a control technology that uses its self-learning ability to adjust system parameters. Based on PID control, BP

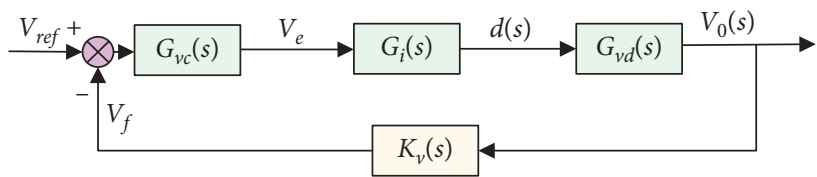

FIGURE 3: Voltage mode control transfer function block diagram.

neural network PID inherits the stability and robustness of traditional PID control and combines the quick learning and adaptive ability of BP neural network. The two control methods complement each other very well. Therefore, they occupy a place in the nonlinear control system. The classical PID controller directly performs the closed-loop control on the controlled object, and the three parameters $K p, K i$, and $K d$ are adjusted online modes. However, these three parameters interact with each other and reinforce or cancel each other within a certain range, consequently, which results in that they are difficult to be controlled. In order to solve this problem, a PID controller based on BP neural network is proposed in the literature [18]. Its structure is demonstrated in Figure 5, which is used to determine the best PID parameters.

In the case of a discrete model, the classical incremental digital PID control algorithm is expressed as

$$
\begin{aligned}
u(k)= & u(k-1)+K_{p}[e(k)-e(k-1)]+K_{i} e(k) \\
& +K_{d}[e(k)-2 e(k-1)+e(k-2)] .
\end{aligned}
$$

3.2. BP Neural Network. BP neural network is a three-layer forward artificial neural network composed of the input layer, hidden layer, and the output layer. In this paper, there are 3 neurons in the input layer and 2 neurons in the output layer, and the number of hidden layers and the number of neurons in each hidden layer are not determined, which depends on simulation results. The structure of BP neural network is illustrated in Figure 6. Inputs are output voltage $V_{\mathrm{dc}}$, output voltage error $e$, and PI controller output value of the previous $y_{-}$last, respectively. Outputs are $K_{p}$ and $K_{i}$, respectively. 


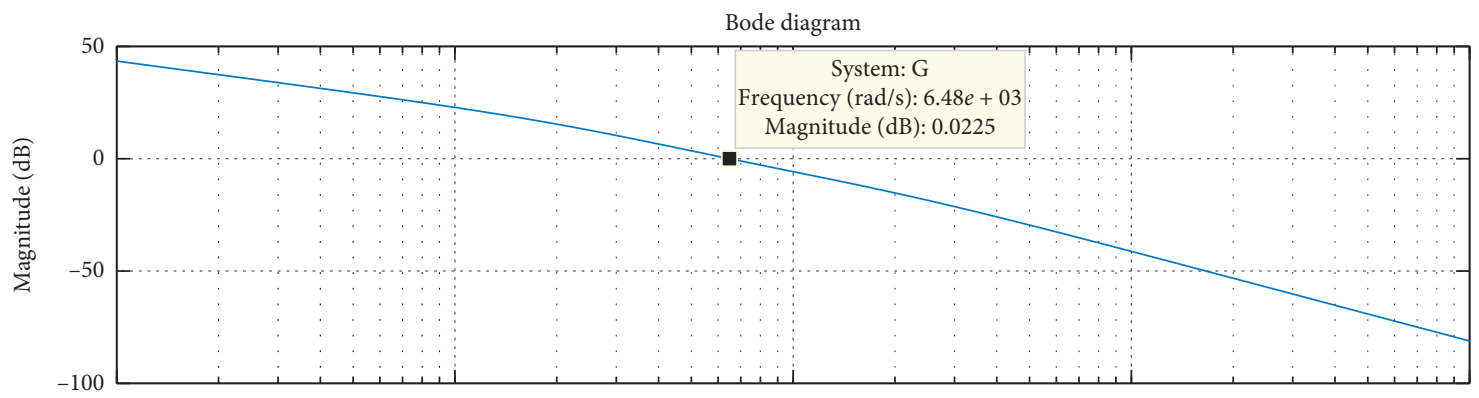

(a)

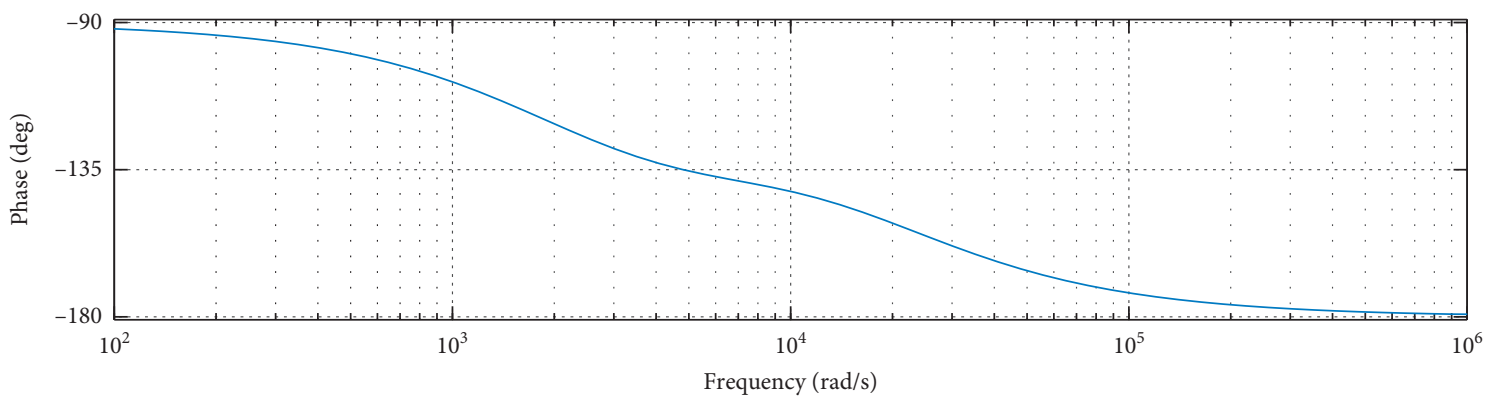

(b)

FIgURE 4: The Bode diagram of the system after correcting.

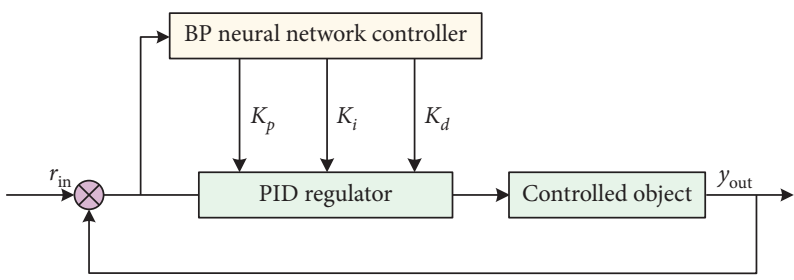

FIgURe 5: PID control system structure of BP neural network.

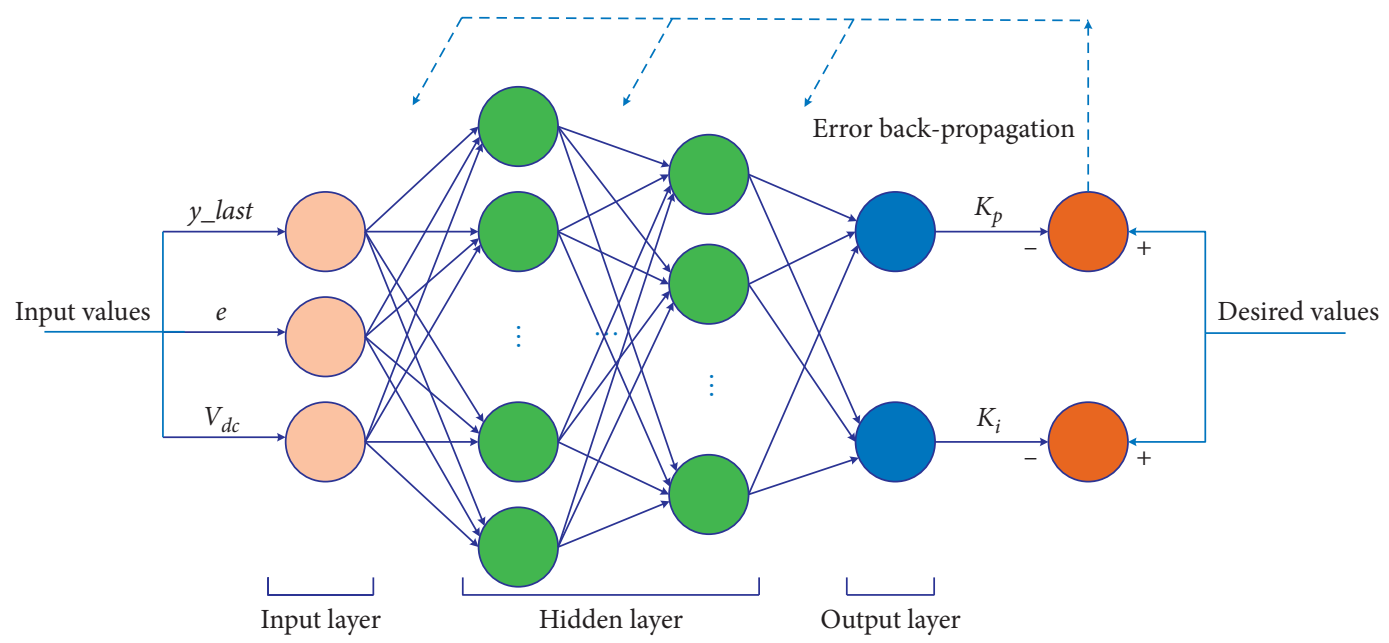

FIGURE 6: Training structure of BP neural network.

The prediction error of BP neural network is not sensitive to the change of weight value, the error gradient changes very little, the number of iterations is large, and the convergence speed is slow. The gradient descent method is easy to fall into local optimum in the process of backward error propagation [19]. Therefore, in practical application, it is necessary to use one certain optimization algorithm to optimize the BP neural network prediction model. 


\subsection{Principle and Performance Analysis of IGA}

3.3.1. Improved GA. First of all, GA needs to determine the scope of search space to form the initial population of genetic space. In order to select the expected individuals, an appropriate fitness function needs to be set, which is the objective function of this paper. By simulating the principle of population mating, individuals with higher adaptability are selected to mate with each other to produce excellent individuals; at the same time, some parts of the variables to be solved are randomly modified to mutate new individuals and continue to select individuals with stronger adaptability; the above process is cycled until the termination conditions are met to obtain the optimal solution $[20,21]$. This paper combines GA with quasi-Newton method to improve the convergence speed and avoid falling into local optimum; the flow chart of the improved GA is shown in Figure 7. Firstly, GA is used for initial optimization, and the optimization process ends when the search scope is reduced to a certain extent. Secondly, the optimal solution obtained by GA is used as the initial value of quasi-Newton method for accurate optimization; when the process of quasi-Newton method is terminated, whether the optimal solution meets the expectation is judged. If the optimal solution meets the expectation, it will be output as the final result. Otherwise, the GA will be used for a certain number of iterations, and the optimal solution will be output as the final result. IGA does not need to find the exact solution, as long as the number of individuals is enough to cover the possible optimal solution [22].

3.4. Design of IGA-BP Neural Network. In the process of BP neural network training, the weights and thresholds are generated randomly. According to the characteristics of chromosomes in genetic evolution, the weight and threshold of BP neural network are coded. The initial population is formed by a certain method, and the error function of BP neural network is taken as the fitness function. The optimal individuals are screened by gene operation, and the corresponding optimal chromosome is used as the weight and threshold of BP neural network. This paper proposes IGA to optimize the weights and thresholds of BP neural network; the following aspects are mainly taken into account.

3.4.1. Encoding Style. Since the weights and thresholds of IGA-BP neural network are real numbers, the real coding scheme is used to encode the weights and thresholds. The topological structure of BP neural network is $3-20-2$; the length of coding is $L=3 \times 20+20+20 \times 2+2=122$. If the population size is too small, the training accuracy of the network will be reduced. If the population size is too large, the convergence speed of the network will be slowed down. In this paper, according to the actual experiment, the population size of 20 was selected.

3.4.2. Selection of Fitness Function. The absolute value of the error between the predicted value of samples of the PID control and the expected value as the individual fitness function is expressed as

$$
f\left(a_{i}\right)=\operatorname{abs}\left(y_{i}-t_{i}\right),
$$

where $i=1,2,3, \ldots, n ; n$ is the number of training samples; $y_{i}$ is the expected value of the $i$ th sample of BP neural network; and $t_{i}$ is the predicted value the $i$ th sample.

Therefore, the IGA-BP neural network model takes the sum of the absolute value of the error between the predicted values of the PID control and the expected value as the global fitness function expressed as

$$
F=\sum_{i=1}^{n} f\left(a_{i}\right) .
$$

The lower the fitness value obtained, the smaller the sum of the absolute errors and, therefore, the better the network performance reached.

3.4.3. Strategies for Genetic Manipulation. Genetic operations include selection, crossover, and mutation. The probability of each individual selected is determined by the fitness. The larger the individual fitness value, the easier it is to be selected. The crossover probability is set to 0.7 and the mutation probability is set to 0.4 .

The selection operator is roulette. The probability of individual $a_{i}$ being selected is

$$
P\left(a_{i}\right)=\frac{f\left(a_{i}\right)}{F} .
$$

When the individual adopts the real number coding, the crossover operation of two different chromosomes $a_{m}$ and $a_{n}$ at $j$ position is

$$
\left\{\begin{array}{l}
a_{m}^{j+1}=a_{m}^{j}(1-b)+a_{n}^{j} b, \\
a_{n}^{j+1}=a_{n}^{j}(1-b)+a_{m}^{j} b .
\end{array}\right.
$$

When the mutation operator mutates the $j-$ th gene of the $i$ - th individual with a certain probability, the mutation operator acts as

$$
a_{i j}= \begin{cases}a_{i j}+\frac{R\left(g_{\max }-g\right)}{g_{\max }}\left(a_{i j}-a_{\max }\right), & R>0.5, \\ a_{i j}+\frac{R\left(g_{\max }-g\right)}{g_{\max }}\left(a_{\min }-a_{i j}\right), & R \leq 0.5 .\end{cases}
$$

Roulette is used as the selection operator in genetic algorithm, $f\left(a_{i}\right)$ is the selection probability of each individual roulette method. $a_{m}^{j}$ and $a_{n}^{j}$ are the parents of genes; $a_{m}^{j+1}$ and $a_{n}^{j+1}$, respectively, are the upper and lower limits of gene which are the offspring after crossing; $b$ is a random number within $[0,1] ; a_{\max }$ and $a_{\min }$, respectively, are the upper and lower limits of the gene; $g$ is the current number of iterations; $g_{\max }$ is the maximum number of iterations; $R$ is a random number within $[0,1]$.

The flow chart of IGA-BP neural network prediction is depicted in Figure 8. 


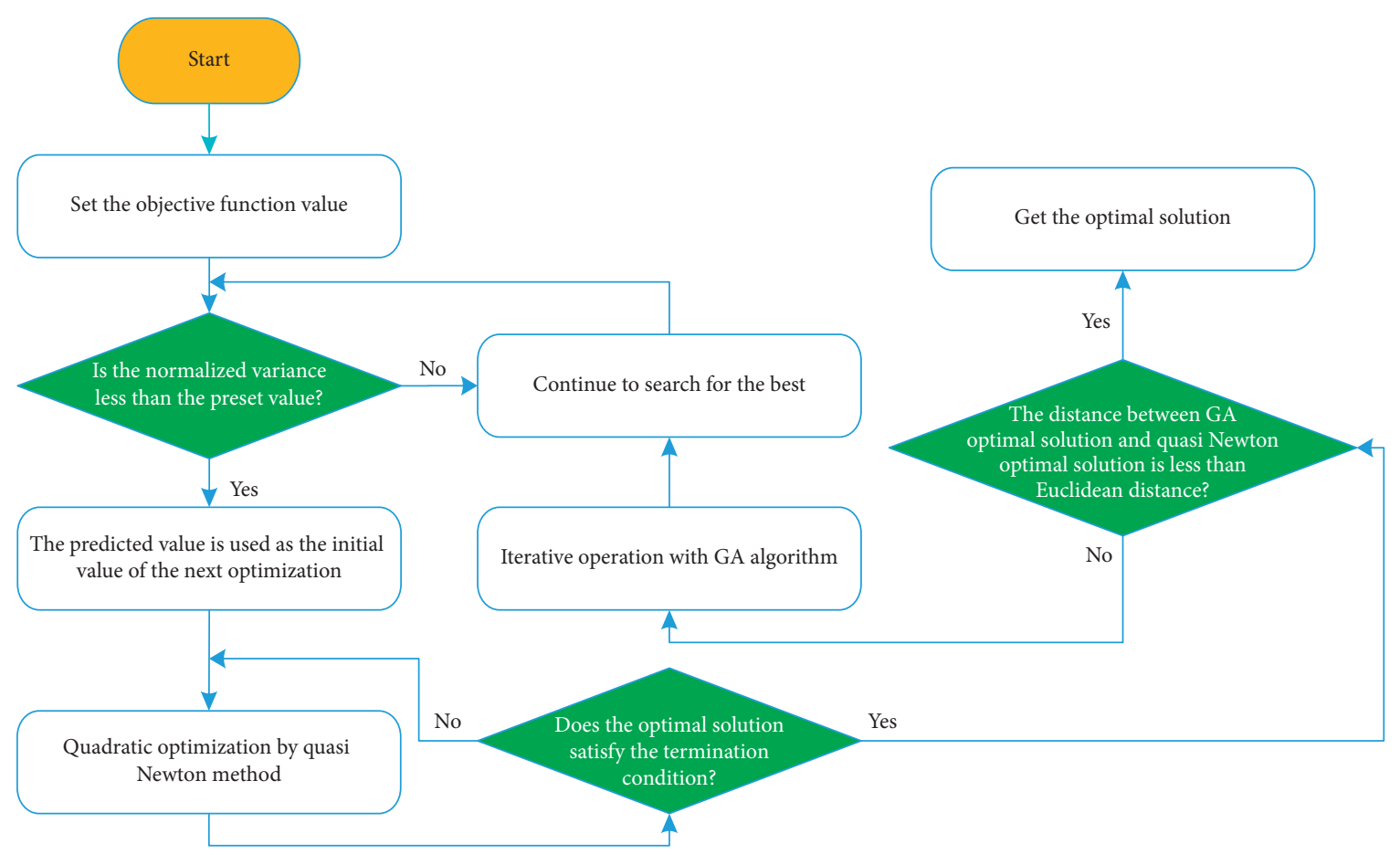

Figure 7: The flow chart of IGA.

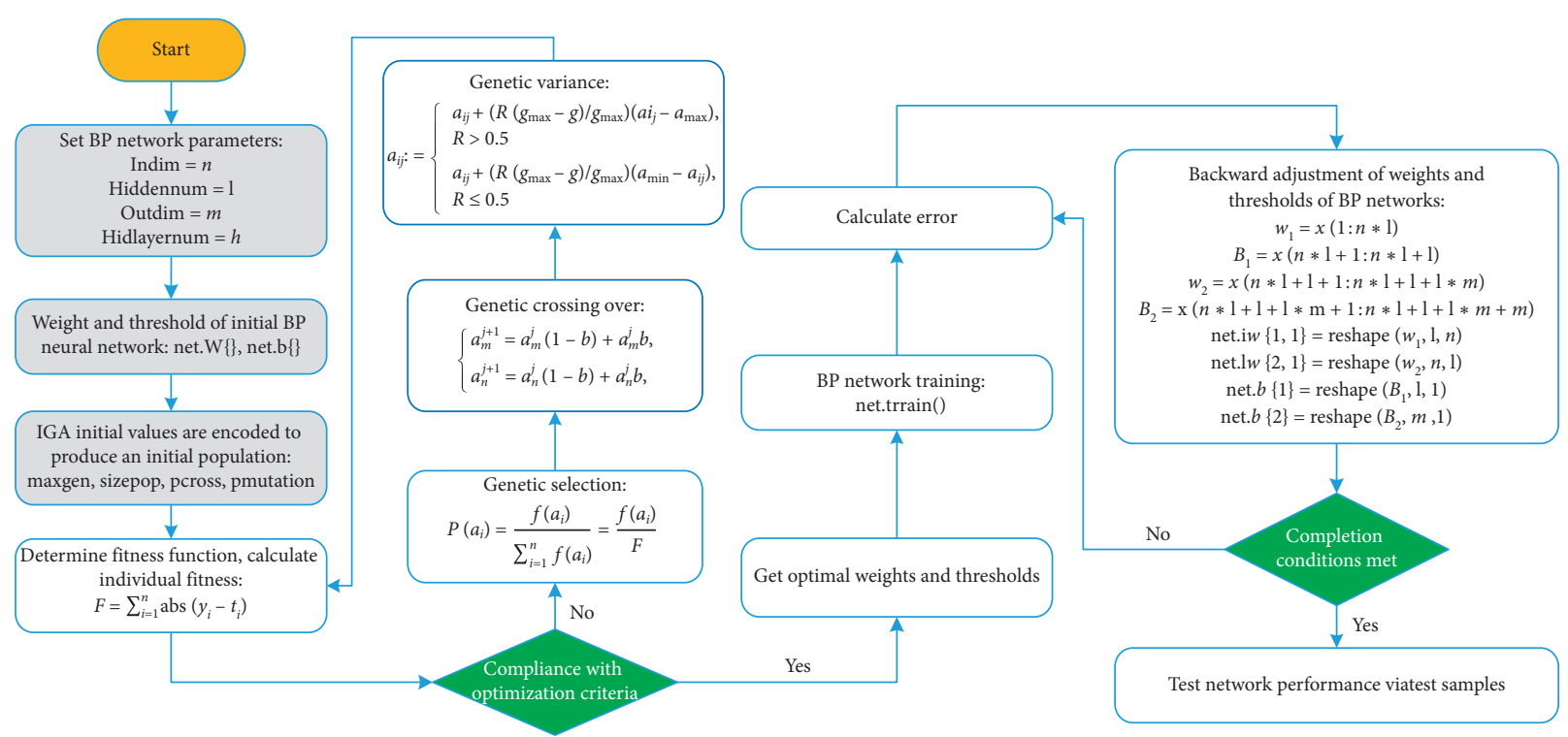

Figure 8: The flow chart of IGA-BP neural network model prediction.

3.5. Analysis of Prediction Accuracy. $K_{p}$ and $K_{i}$ predicted by BP neural network, GA-BP neural network, and IGA-BP neural network are obtained in Figures 9 and 10, respectively.

The error values of $K_{p}$ predicted by the three models can be obtained in Figure 9, among which the prediction error of BP neural network is within \pm 0.01 , and the error fluctuates greatly; the error of GA-BP neural network is within \pm 0.005 , which is less than that of BP neural network; and the error of IGA-BP neural network is within \pm 0.0004 . Therefore, it is obvious that IGA-BP neural network has the minimum prediction error of $K_{p}$.

The error values of $K_{i}$ predicted by the three models can be obtained in Figure 10. Among them, the prediction error of BP neural network is within \pm 0.5 ; the error of GA-BP neural network is within \pm 0.02 , which is less than that of BP neural network; and the error of IGA-BP neural network is within \pm 0.005 . Therefore, it is obvious that IGA-BP neural network has the minimum prediction error of $K_{i}$. 


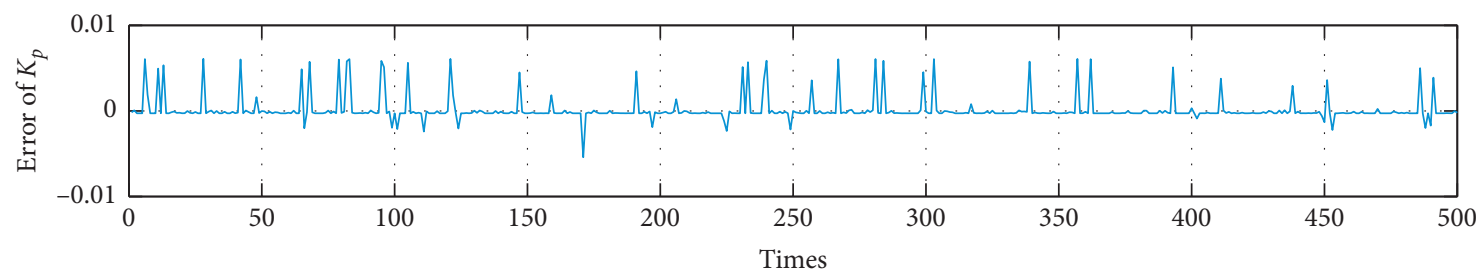

(a)

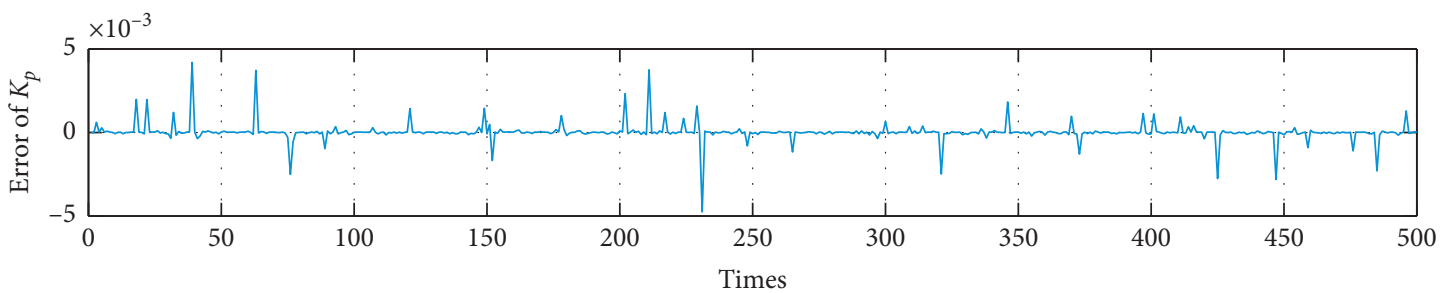

(b)

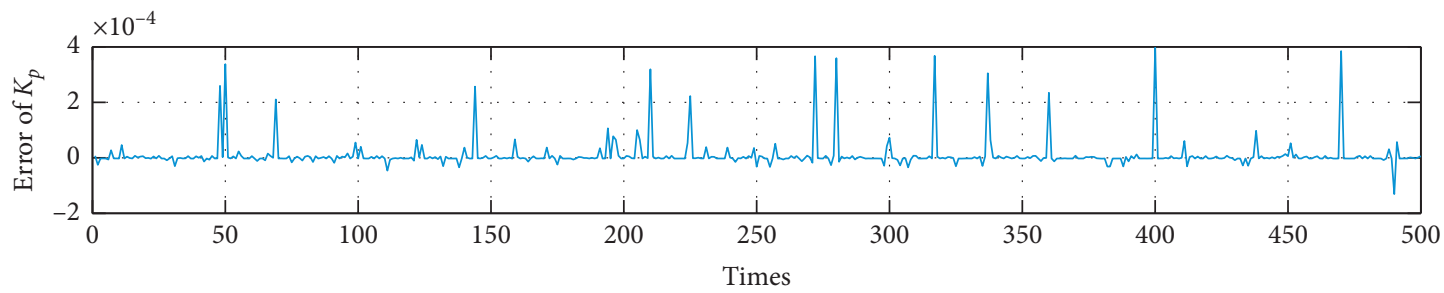

(c)

Figure 9: Error of Kp. (a) Error of BP. (b) Error of GA-BP. (c) Error of IGA-BP.

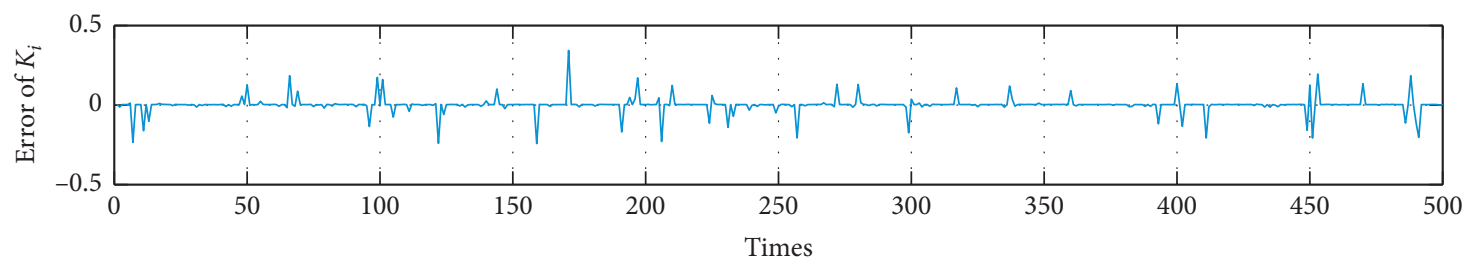

(a)

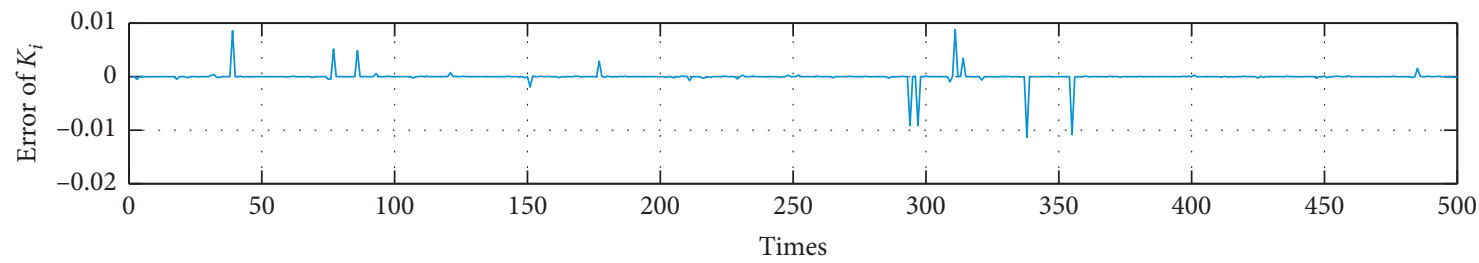

(b)

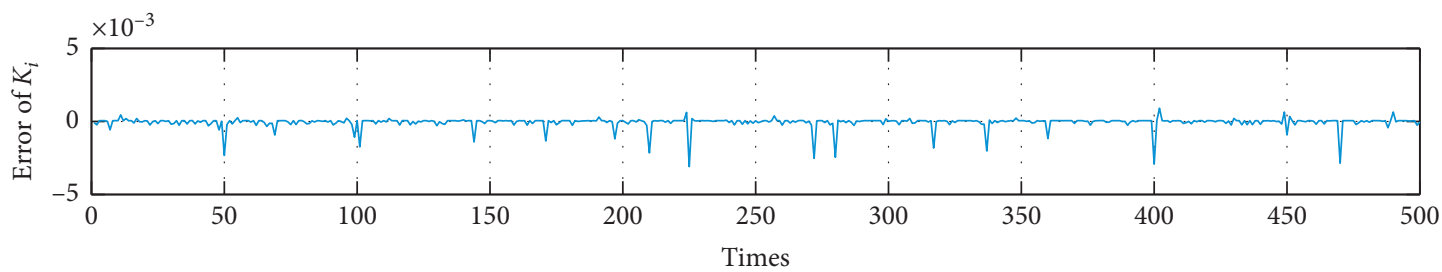

(c)

Figure 10: Error of $K_{i}$. (a) Error of BP. (b) Error of GA-BP. (c) Error of IGA-BP. 
Therefore, the prediction result of the optimized model is better than that of the traditional BP network. The result of GA-BP model is better than that of BP network. Because the convergence of IGA is better than that of GA, the prediction result of IGA-BP prediction model is the closest to the actual value of PID.

Three models reflect the general situation of PID parameter prediction, and the error results are summarized in Table 1. The mean square error of GA-BP neural network is smaller than that of BP neural network, and the mean square error of IGA-BP neural network is the smallest. Consequently, the prediction accuracy of BP neural network is low, and the prediction effect is unstable; however, the prediction accuracy of IGA-BP neural network is the highest, which is suitable for the prediction of PID parameters.

\section{Simulation and Analysis}

4.1. Simulation Parameters. In this paper, MATLAB/ Simulink is used to establish the simulation model of phaseshifted full-bridge DC/DC rectifying converter with currentdoubler synchronous rectifier. Main parameters of the circuit are summarized in Table 2.

The parameters of the optimized neural network PID are summarized in Table 3. Major part of the calculation process is as follows.

Input of input layer:

$$
x_{i}=\left[y_{-} \text {last, } e, V_{\mathrm{dc}}\right] \text {. }
$$

Sum of hidden layers:

$$
\operatorname{web}_{i j}=\sum_{i=0}^{n} w_{-} i j \cdot x_{i} .
$$

Output of hidden layer:

$$
z=\frac{e^{\mathrm{web}_{i j}}-e^{-\mathrm{web}_{i j}}}{e^{\mathrm{web}_{i j}}+e^{-\mathrm{web}_{i j}} .}
$$

Sum of output layers:

$$
\mathrm{web}_{j k}=\sum_{i=0}^{n} w_{-} j k \cdot z_{j} .
$$

Output of the Output layer is PI coefficients, namely, $K p$ and $K i$; they compose an array as

$$
y=\frac{e^{\mathrm{web}_{j k}}}{e^{\mathrm{web}_{j k}}+e^{-\mathrm{web}_{j k}} .}
$$

Output of PID controller:

$$
y=y_{-} \text {last }+K_{-} \mathrm{PI}(1) \cdot\left(e-e_{-} \text {last }\right)+K_{-} \mathrm{PI}(2) \cdot e .
$$

Prediction structure of BP neural network can be obtained in Figure 11.

4.2. Analysis of Simulation Results. The switching states of $Q_{1}, Q_{2}, Q_{3}$, and $Q_{4}$ can be obtained in Figure 12, respectively, and $\mathrm{VS}_{1}, \mathrm{VS}_{2}, \mathrm{VS}_{3}$, and $\mathrm{VS}_{4}$ are the corresponding driving signals of $Q_{1}, Q_{2}, Q_{3}$, and $Q_{4}$, respectively. $V_{1}$ and $V_{4}$ are
TABLE 1: Error of prediction results.

\begin{tabular}{lcccccc}
\hline Error & \multicolumn{2}{c}{ Model of BP } & \multicolumn{2}{c}{ Model of GA-BP } & \multicolumn{2}{c}{ Model of IGA-BP } \\
\hline Type & $K_{p}$ & $K_{i}$ & $K_{p}$ & $K_{i}$ & $K_{p}$ & $K_{i}$ \\
MSE & 0.0022 & 0.0062 & $5.27 e-5$ & $6.99 e-4$ & $9.36 e-6$ & $3.79 e-4$ \\
MAE & 0.0023 & 0.0062 & $5.28 e-5$ & $7.04 e-4$ & $8.27 e-6$ & $3.05 e-4$ \\
RMSE & 0.0031 & 0.0088 & $7.45 e-5$ & $9.88 e-5$ & $8.75 e-6$ & $4.22 e-5$ \\
\hline
\end{tabular}

phase shifted and the conduction time is interleaved. The state between $\mathrm{VS}_{2}$ and $\mathrm{VS}_{3}$ is the same state between $\mathrm{VS}_{1}$ and $\mathrm{VS}_{4}$. Therefore, $\mathrm{VS}_{1}$ and $\mathrm{VS}_{4}$ as a whole are interleaved with $\mathrm{VS}_{2}$ and $\mathrm{VS}_{3}$, which accords with the characteristics of phase-shifting full-bridge circuit. $S_{1}$ and $S_{2}$ are the driving signals of the synchronous transistors $Q_{5}$ and $Q_{6}$, respectively, which are generated by $\mathrm{VS}_{1}-\mathrm{VS}_{4}$ logic combination $\mathrm{SR}_{1}=\overline{\mathrm{VS}_{1} \cdot \mathrm{VS}_{4}}, \mathrm{SR}_{2}=\overline{\mathrm{VS}_{2} \cdot \mathrm{VS}_{3}}$.

The voltage and current of the lagging leg can be obtained in Figure 13. It is obvious that the voltage and current of the two switches are interleaved; consequently, zero voltage turn-on is realized.

The voltage and current of the secondary side of the transformer can be obtained in Figure 14. The output voltage and current of the inverter circuit are ideal square wave alternating current.

Figure 15 shows the efficiency of the rectifying converter based on different power devices. Under the same input and output conditions, it can be seen that the efficiency of current-doubler synchronous rectifying converters (CDSRC) is always higher than that of the rectifying converter using common current-doubler rectifier (CDRC). And the efficiency can be increased approximately $2.3 \%$ at the maximum efficiency. Moreover, results indicate that the efficiency is up to $92 \%$ above and the highest efficiency is up to $94.1 \%$ in a range of load of $1 / 3$ and rated load. It is proved that the synchronous rectification technology plays an important role of improving the efficiency in the rectifying converter. Compared with the secondary side power converter using MOSFET rectifying converter, the rectifying converter based on IGBT designed in this paper has a smaller power loss and a higher efficiency.

The current of two filter inductors of current-doubler rectifier can be obtained in Figure 16(a), and the stable load current obtained by different control algorithms can be obtained in Figure 16(b). For PSFB-CDSRC, the currents generated by PID algorithm and IGA-BP neural network algorithm are synthesized by two filter inductors, and the ripple amplitudes are almost the same. Compared with the conventional PSFB model, it is obvious that the PSFBCDSRC has a smaller ripple factor and a better performance.

Performances of different PID control strategies are obtained in Figure 17. Under the same conditions, the voltage overshoot exists in PID and BP neural network PID control; however, GA-BP neural network PID and IGA-BP neural network PID can achieve no overshoot. When IGA-BP neural network PID is used, the voltage and current reach steady state at $0.095 \mathrm{~s}$ and are maintained at $5 \mathrm{~V} / 500 \mathrm{~A}$. When GA-BP neural network PID is used, the voltage and current reach steady state at $0.105 \mathrm{~s}$ and are maintained at $5 \mathrm{~V} / 500 \mathrm{~A}$. Therefore, in the response speed, 
TABLE 2: Main parameters of the circuit.

\begin{tabular}{lccccccccc}
\hline$V_{i}$ & $L_{r}$ & $C_{1} / C_{2}$ & $C_{3} / C_{4}$ & $C_{b}$ & $L_{f 1} / L_{f 2}$ & $C_{f}$ & $f_{s}$ & $t_{d}$ & $n$ \\
\hline $24 \mathrm{~V}$ & $0.1 \mu \mathrm{H}$ & $2 \mu \mathrm{F}$ & $80 \mathrm{pF}$ & $500 \mu \mathrm{F}$ & $1 \mu \mathrm{H}$ & $0.5 \mathrm{mF}$ & $20 \mathrm{kHz}$ & $1 \mu \mathrm{s}$ & 2 \\
\hline
\end{tabular}

TABLE 3: Parameters of IGA-BP neural network.

\begin{tabular}{lcc}
\hline Parameters & Value \\
\hline The voltage reference's specified value $V_{\mathrm{dc} \_}$ref & $5 \mathrm{~V}$ \\
The output value of main circuit voltage & $V_{\mathrm{dc}}$ \\
Error $e$ & $V_{\mathrm{dc}}-V_{\mathrm{dc} \_}$ref \\
Number of neurons in the input layer & 3 \\
Number of neurons in the hidden layer & 20 \\
Number of neurons in the output layer & 2 \\
Output of PI controller & $y$ \\
Output of PI controller at the previous clock tick & $y_{\text {_last }}$ \\
Error at the previous clock tick & $V_{\mathrm{dc} \_l a s t}$ \\
Voltage at the previous clock tick & $w_{i j}$ \\
Weight coefficient from input layer to hidden layer & $w_{j k}$ \\
Weight coefficient from hidden layer to output layer & $b_{i j}$ \\
Threshold coefficient from input layer to hidden layer & $b_{j k}$ \\
Threshold coercion from hidden layer to output layer &
\end{tabular}

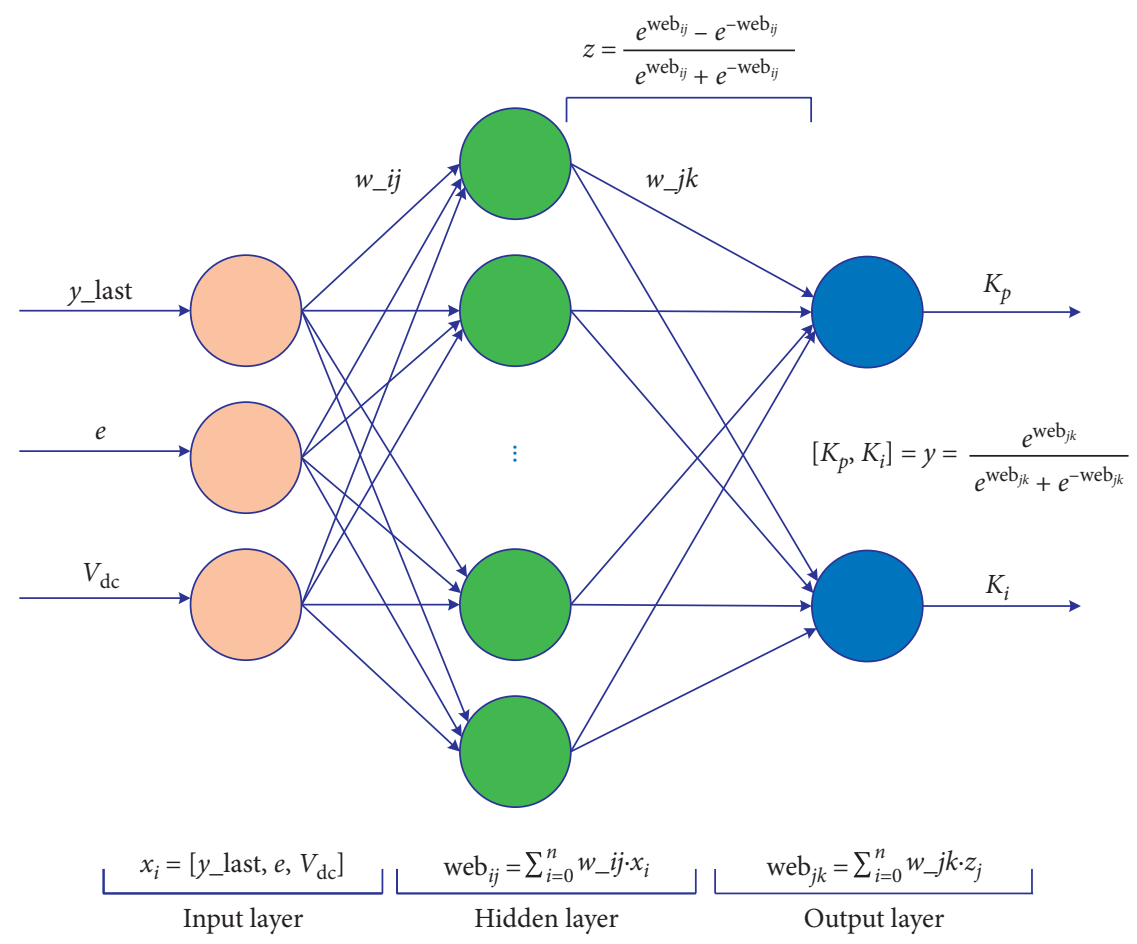

Figure 11: Prediction structure of BP neural network.

IGA-BP neural network PID is faster than GA-BP neural network PID; IGA-BP neural network PID has a better steady state performance and is suitable for phase-shift full-bridge current-doubler synchronous rectification DC/ DC rectifying converter.

In this study, the maximum output power (the rated power) of the rectifying converter is $5 \mathrm{~V} * 500 \mathrm{~A}=2.5 \mathrm{Kw}$ which corresponds the maximum allowed rated load $R_{L}=0.01 \Omega$. To verify the wider load ranges of the rectifying converter, the different loads $R_{L}$ of $10 \%=0.1 \Omega, R_{L}$ of $50 \%=0.02 \Omega, R_{L}$ of $80 \%=0.0125 \Omega$ corresponding to the rated power of $10 \%$, the rated power of $50 \%$, the rated power of $80 \%$ are set up, respectively. Moreover, in order to further test the adjustment ability of the rectifying converter 


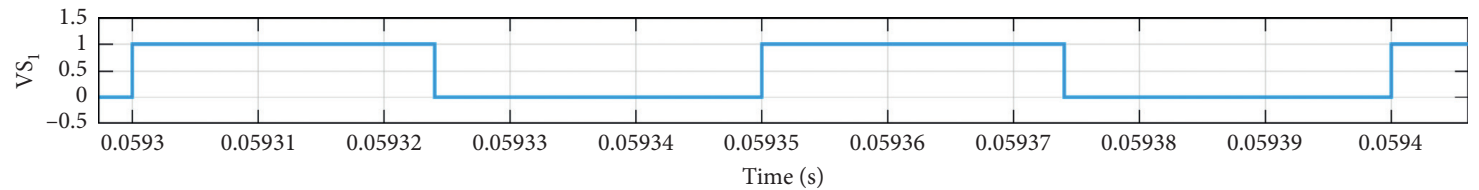

(a)

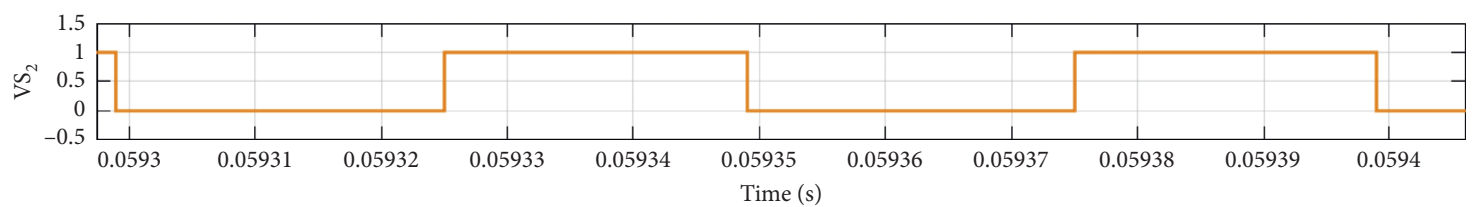

(b)

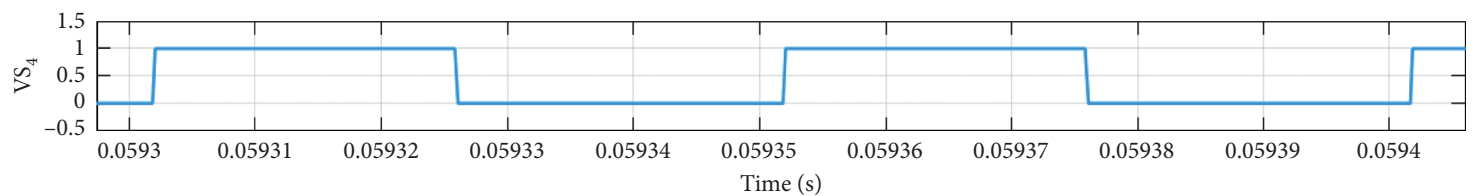

(c)

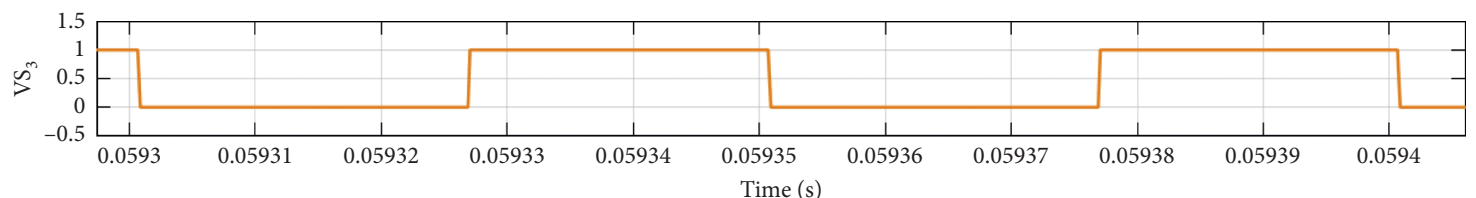

(d)

FIgURE 12: The switching states of IGBT.

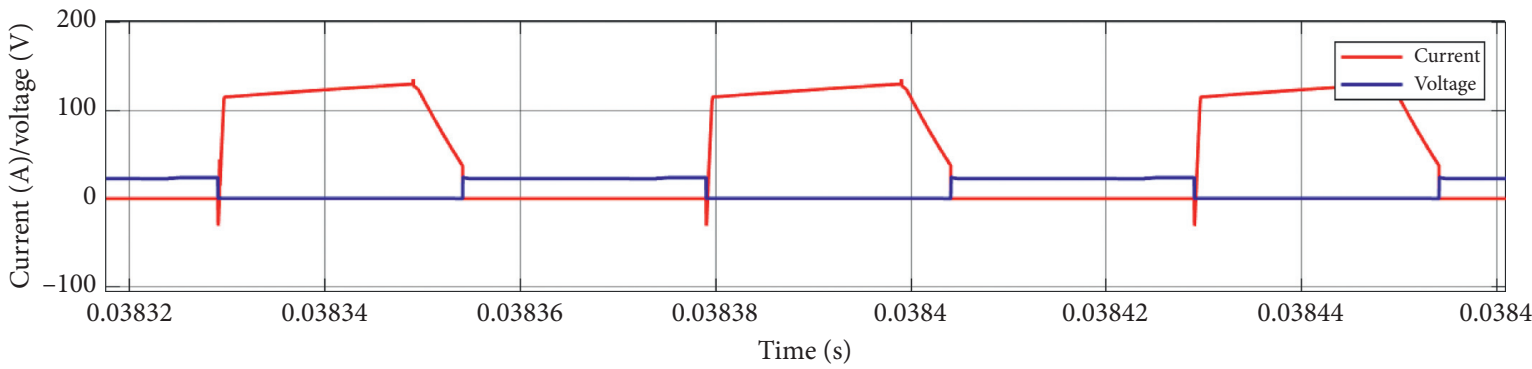

(a)

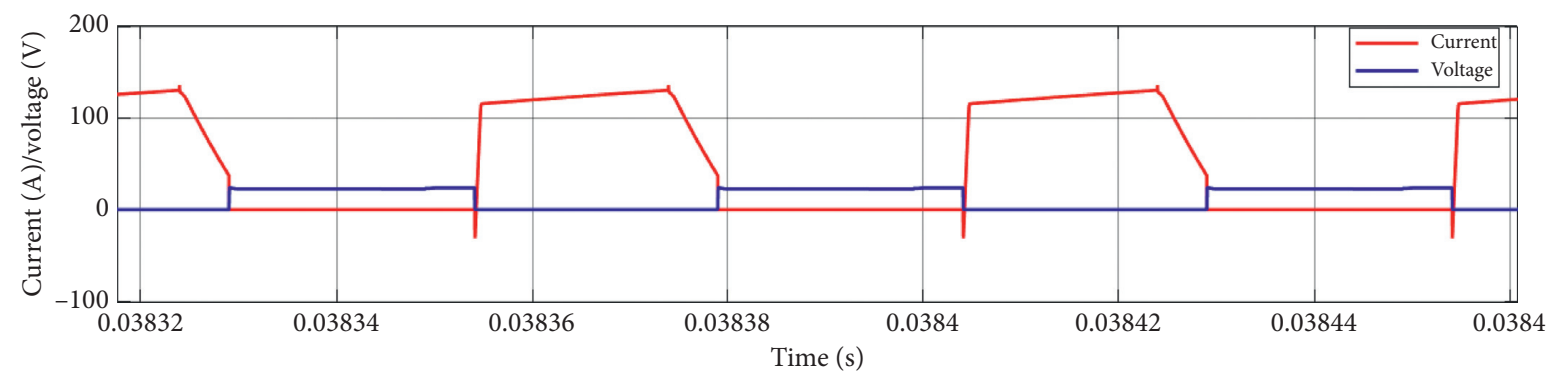

(b)

FIgURE 13: Voltage and current of the lagging leg. (a) Current and voltage of $\mathrm{IGBT}_{3}$. (b) Current and voltage of IGBT 4 .

according to the load changes, the load is increased up to its $10 \%$ at $0.1 \mathrm{~s}$, and the increased part is removed at $0.2 \mathrm{~s}$. Test results are obtained in Figure 18. Therefore, the phase-shift full-bridge current-doubler synchronous rectifying circuit can achieve ZVS of all switches in a wide load range and then output the stable voltage and the current. The test results demonstrate that, compared with the conventional PID, IGA-BP PID can quickly reach the stable state when the load changes, and IGA-BP neural network PID has smaller fluctuations of voltage and current. 


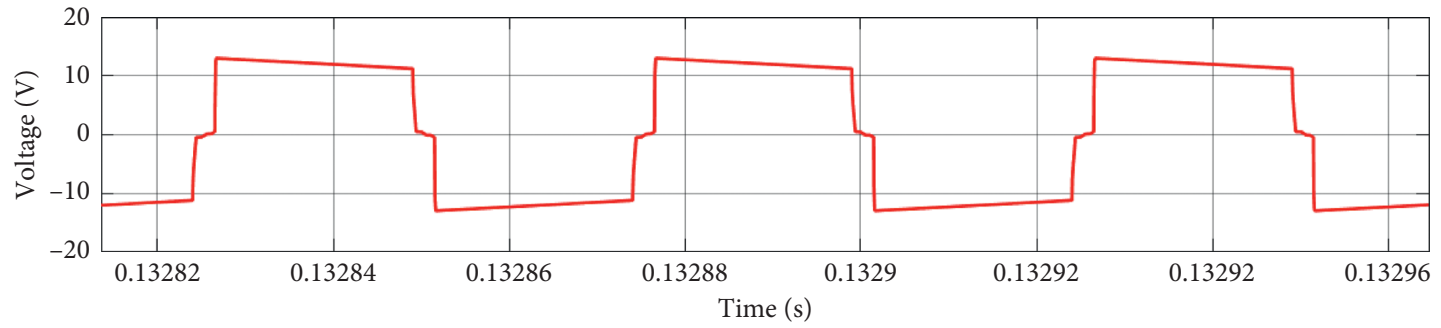

(a)

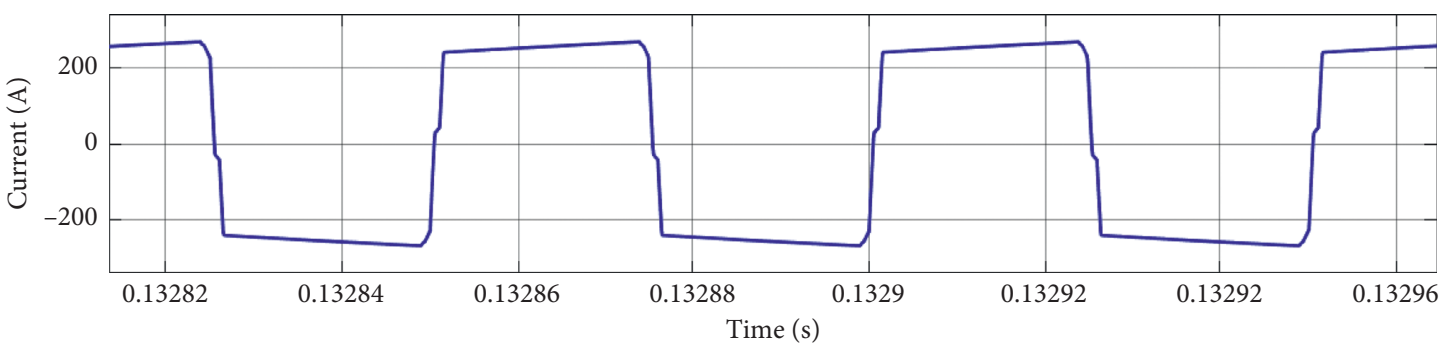

(b)

FIGURE 14: Voltage and current of the secondary side. (a) Voltage of transformer. (b) Current of transformer.

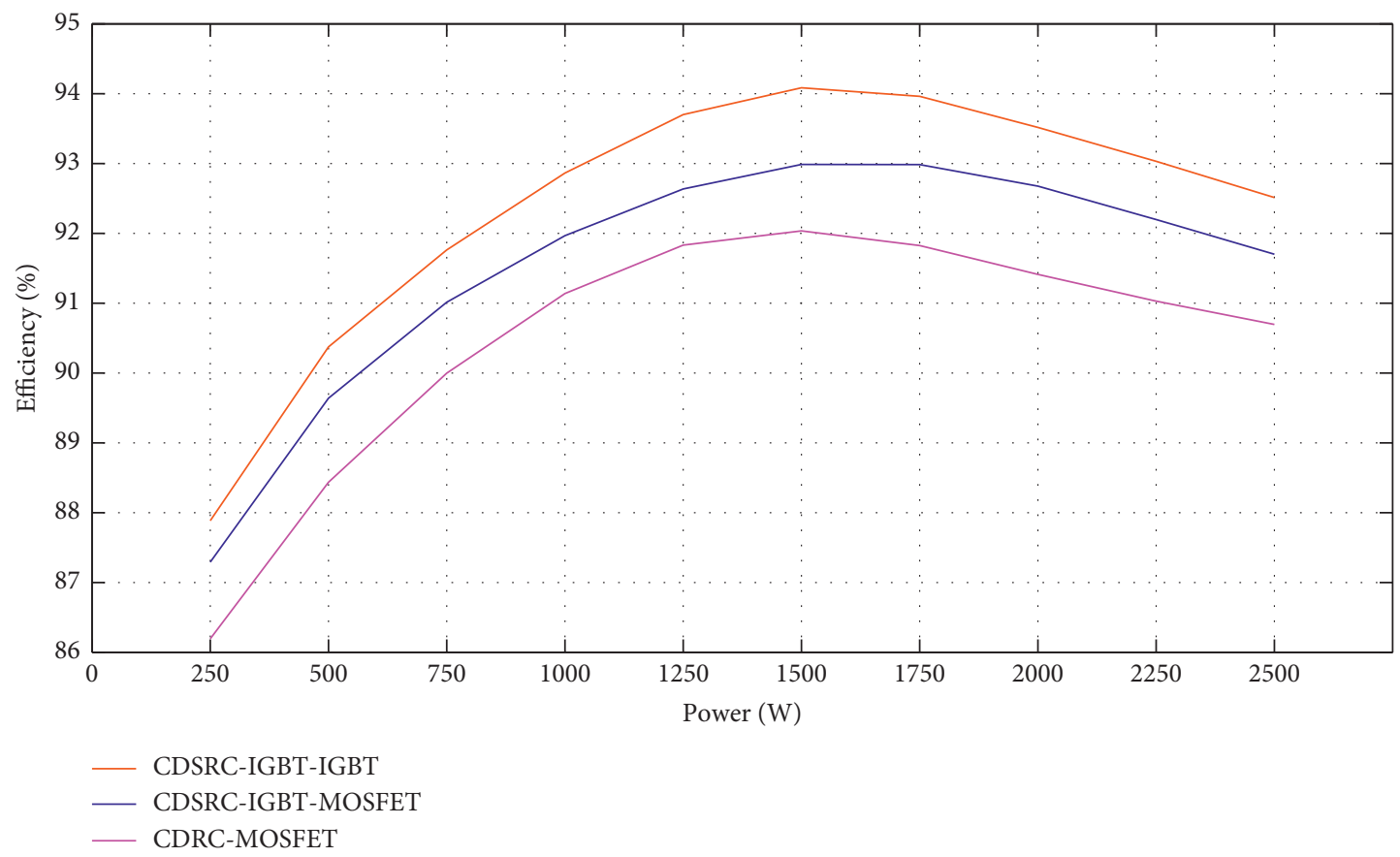

Figure 15: The efficiency of the rectifying converter with different power devices.

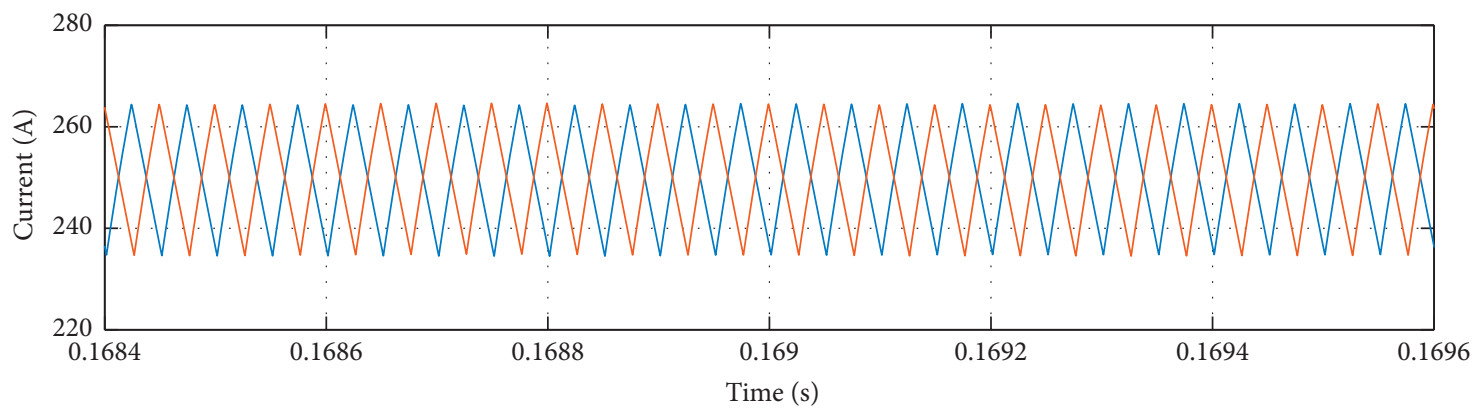

Current of the filter inductors 1

_ Current of the filter inductors 2

(a)

Figure 16: Continued. 


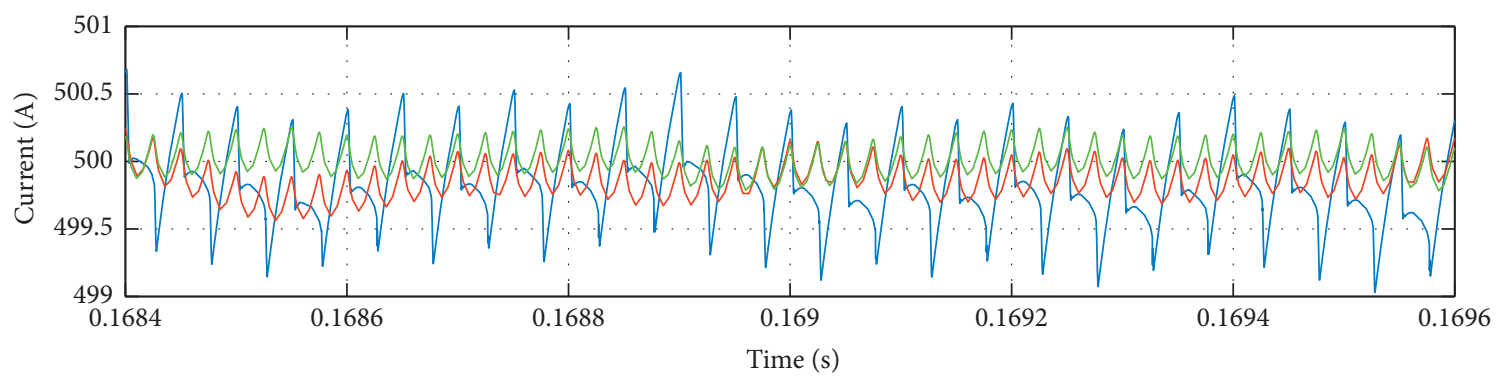

- PSFB-PID

- PSFB-CDSRC-IGA-BP

— PSFB-CDSRC-PID

(b)

Figure 16: Filter inductor current and the load current. (a) Current of the filter inductors. (b) Load current.

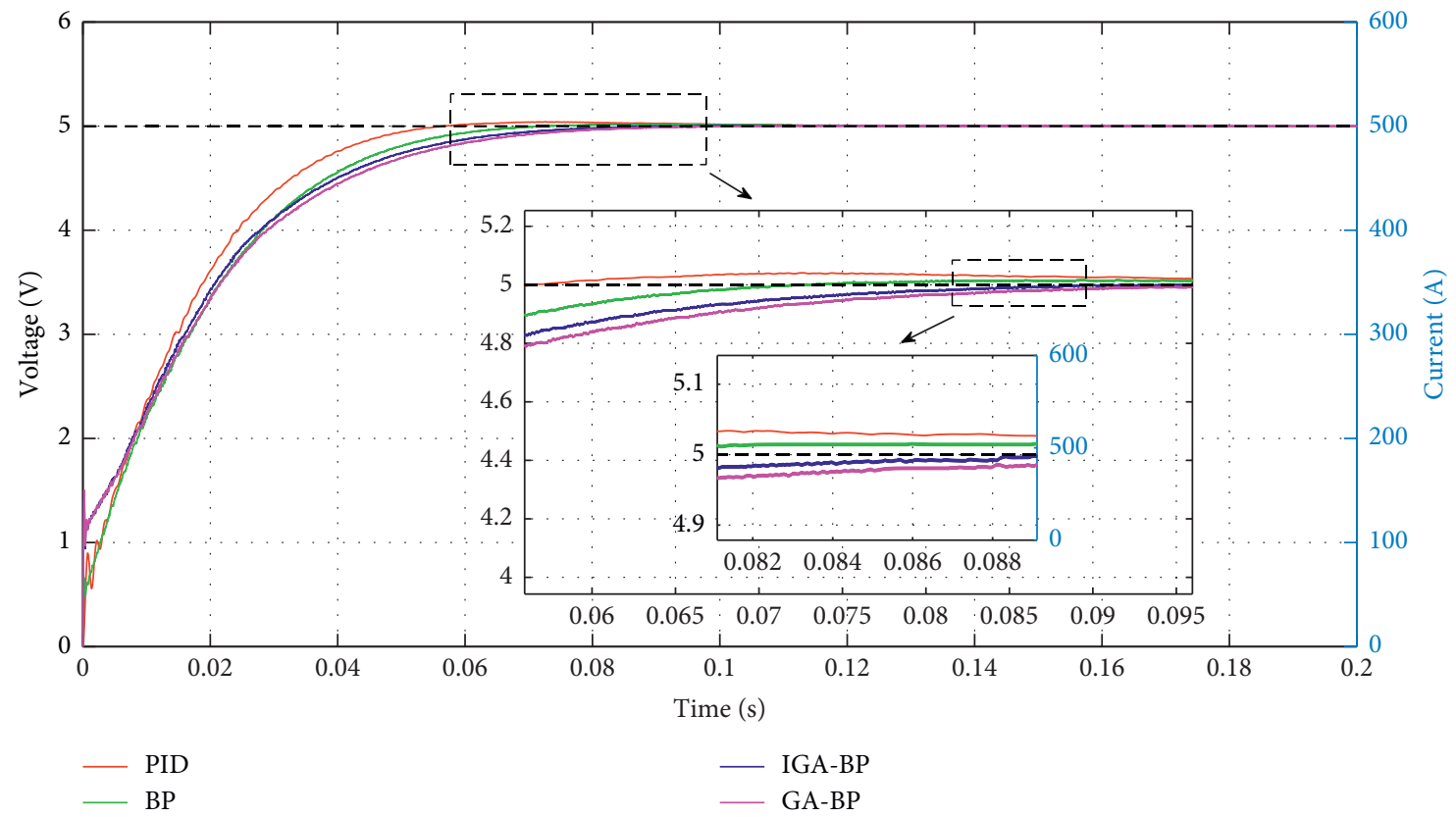

FIGURE 17: Voltage and current control effects.
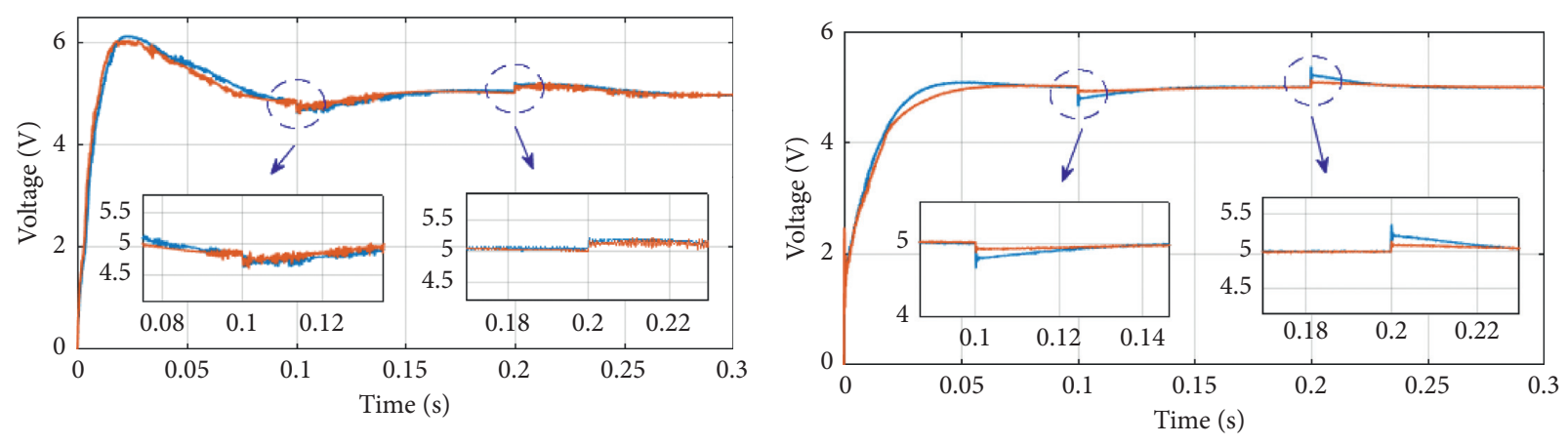

— PID

_ IGA-BP

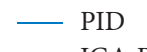

— IGA-BP

(a)

(b)

FIgURE 18: Continued. 


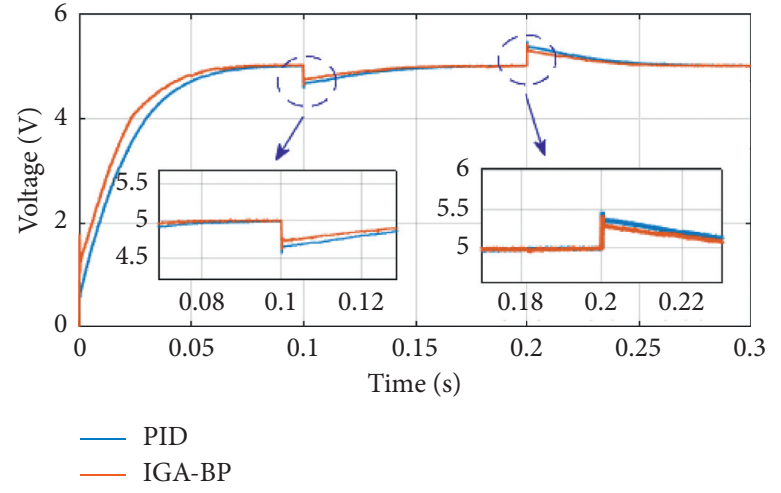

(c)

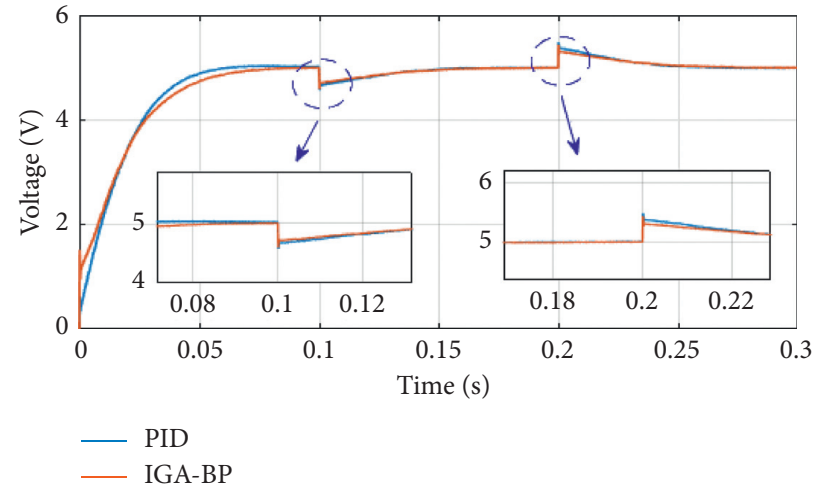

(d)

Figure 18: Load voltage of different rated powers. (a) Load voltage of $10 \%$ rated power. (b) Load voltage of $50 \%$ rated power. (c) Load voltage of $80 \%$ rated power. (d) Load voltage of $100 \%$ rated power.

\section{Conclusions}

In this paper, the phase-shifting full-bridge topology and current-doubler synchronous rectification are combined to compose the main circuit of the entire system. The resonant inductor and the junction capacitance of IGBT are used to construct the quasi-resonant circuit, which realizes the fullbridge switch ZVS. The rectifying converter adopts currentdoubler synchronous rectification based IGBT in the secondary of the transformer, which can reduce the switching loss and decrease the current ripple. Simulation results verify that the maximum efficiency of $94.1 \%$ of 5 V/500 A rectifying converter can be reached in range of load of $1 / 3$ and rated load; consequently, the efficiency can be increased approximately $2.3 \%$ at the maximum efficiency, which indicates that the rectifying converter has a good performance of excellent waveform and wide range of load. On the basis of the proposed main circuit, taking into account the fact that only basic BP neural network PID control was analyzed in exiting researches, this paper presents an IGA-BP neural network PID control strategy to further improve the PID control performance of the rectifying converter, which can effectively compensate for the shortcomings of BP neural network. Comprehensive test results demonstrate that, under the same conditions, GA-BP neural network PID and IGA-BP neural network PID can achieve steady state without overshoot. When IGA-BP neural network PID is used, the voltage and current reach steady state at $0.095 \mathrm{~s}$ and are maintained at $5 \mathrm{~V} / 500 \mathrm{~A}$. When GA-BP neural network PID is used, the voltage and current reach steady state at $0.105 \mathrm{~s}$ and are maintained at $(5 \mathrm{~V} / 500 \mathrm{~A})$; the steady-state time can be reduced by $10.5 \%$ through using IGA-BP neural network control strategy, which indicates that IGA-BP neural network PID control strategy can realize the optimal PID control for phase-shift full-bridge rectifying converter with current-double synchronous rectification. And the proposed phase-shift full-bridge current-doubler synchronous rectifying converter based on IGA-BP neural network control strategy can provide a valuable reference for the development and design of high efficiency intelligent rectifying power supply. For further improving the performance of PID control in phase-shift full-bridge current-doubler synchronous rectifying converter, some other new advanced optimization algorithms should be studied in the future.

\section{Data Availability}

The data used to support the findings of this study are available from the corresponding author upon request.

\section{Conflicts of Interest}

The authors declare that there are no conflicts of interest regarding the publication of this paper.

\section{Acknowledgments}

This work was supported by the Education Department of Jilin Province (Grant JJKH20200044KJ), the Jilin Provincial Development and Reform Commission (Grant 2018C0351), Jilin Provincial Science and Technology Department (Grant 20190101018JH), and Project of Beihua University (Grant 201901012).

\section{References}

[1] J. Everts, F. Krismer, J. Van den Keybus, J. Driesen, and J. W. Kolar, "Optimal ZVS modulation of single-phase singlestage bidirectional DAB AC-DC converters," Ieee Transactions on Power Electronics, vol. 29, no. 8, pp. 3954-3970, 2014.

[2] Z. Zhang, Z. Ouyang, O. C. Thomsen, and M. A. E. Andersen, "Analysis and design of a bidirectional isolated DC-DC converter for fuel cells and supercapacitors hybrid system," Ieee Transactions on Power Electronics, vol. 27, no. 2, pp. 848-859, 2012.

[3] X. Z. Liu, "Dissipation analysis of IGBT module in FBZVZCS-PWM converter," in Advances in Mechatronics and Control Engineering Ii, Pts 1-3, K. Galkowski and Y. H. Kim, Eds., vol. 433-435, p. 1347, Applied Mechanics and Materials, London, UK, 2013.

[4] X. C. Zhu, D. H. Xu, H. Umida, and K. Mino, "Current-fed phase shift controlled full bridge ZCS DC-DC converter with reverse block IGBT," in Apec 2005: Twentieth Annual Ieee 
Applied Power Electronics Conference and Exposition, vol. 1-3, pp. 1605-1610, Annual IEEE Applied Power Electronics Conference and Exposition (APEC), London, UK, 2005.

[5] R. Rong and S. Zeljkovic, "High speed IGBT based HV-lv DC/ DC converter for electric vehicle," in 2014 Ieee Transportation Electrification Conference and ExpoIEEE Transportation Electrification Conference and Expo Asia-Pacific, London, UK, 2014.

[6] H. Song, Y. Zhang, and Y. Zhang, "An improved current-doubler rectifier for the marine controlled source electromagnetic transmitter," Mathematical Problems in Engineering, vol. 2018, 2018.

[7] H. Phuc and A. Banerjee, "Active voltage-ripple compensation in an integrated generator-rectifier system," in Proceedings of the Thirty-Fourth (Annual IEEE Applied Power Electronics Conference and Exposition (APEC), pp. 3199-3206, London, UK, 2019.

[8] H.-J. Chiu and L.-W. Lin, "A high-efficiency soft-switched AC/DC converter with current-doubler synchronous rectification," Ieee Transactions on Industrial Electronics, vol. 52, no. 3, pp. 709-718, 2005.

[9] Y. Pang and G. Liang, "A high efficiency control-driven method for synchronous rectifier in the symmetrical half-bridge converter with current-doubler," Power Electronics, vol. 38, no. 4, pp. 74-76, 2004.

[10] Z. B. Luo and W. Li, "Tracking of mobile robot expert PID controller design and simulation," International Symposium on Computer, Consumer and Control, vol. 2014, pp. 566-568, 2014.

[11] M. Rabah, A. Rohan, and S.-H. Kim, "Comparison of position control of a gyroscopic inverted pendulum using PID, fuzzy logic and fuzzy PID controllers," International Journal of Fuzzy Logic and Intelligent Systems, vol. 18, no. 2, pp. 103-110, 2018.

[12] C. Ma, S. Z. Tian, X. M. Xiao, and Y. Q. Jiang, "Fuzzy Neural Network PID-based constant deceleration compensation device for the brakes of mining hoists," Advances in $\mathrm{Me}$ chanical Engineering, vol. 12, no. 7, 2020.

[13] Y.-M. Cheng, C. Liu, J. Wu et al., "A back propagation neural network with double learning rate for PID controller in phase-shifted full-bridge soft-switching power supply," Journal of Electrical Engineering \& Technology, vol. 15, no. 6, pp. 2811-2822, 2020.

[14] J. Liu, X. J. Li, X. L. Zhang, and X. F. Chen, "Modeling and simulation of energy-regenerative active suspension based on BP neural network PID control," Shock and Vibration, vol. 2019, 2019.

[15] H. Y. Hong, P. Tsangaratos, I. Ilia, C. Loupasakis, and Y. Wang, "Introducing a novel multi-layer perceptron network based on stochastic gradient descent optimized by a meta-heuristic algorithm for landslide susceptibility mapping," Science of the Total Environment, vol. 742, 2020.

[16] X. D. Luan, Q. Y. Di, and D. Lei, "Near-field correction of CSAMT data based on Newton iteration method and GA method," Chinese Journal of Geophysics-Chinese Edition, vol. 61, no. 10, pp. 4148-4159, 2018.

[17] G. Wang and J. Gao, "Parallel conjugate gradient-particle swarm optimization and the parameters design based on the polygonal fuzzy neural network," Journal of Intelligent \& Fuzzy Systems, vol. 37, no. 1, pp. 1477-1489, 2019.

[18] Q. S. Wang, D. L. Liang, and J. H. Du, "Performance study of solid state transformer applying BP artificial neural network pid regulator," 2014.
[19] Y. Y. Sun, H. T. Shan, W. J. Zhang, L. J. Ren, and P. H. Yan, "Reliability prediction of distribution network based on PCA-GA-BP neural network," in Materials Science, Energy Technology and Power Engineering Iii, Z. You, J. Xiao, and Z. Tan, Eds., Vol. 2154, AIP Conference Proceedings, London, UK, 2019.

[20] N. H. M. Nezhad, M. G. Niasar, A. M. Gheidari, C. W. Hagen, and P. Kruit, "Multi-electrode lens optimization using genetic algorithms," International Journal of Modern Physics A, vol. 34, no. 36, 2019.

[21] D. Dutta, J. Sil, and P. Dutta, "Automatic clustering by multi-objective genetic algorithm with numeric and categorical features," Expert Systems with Applications, vol. 137, pp. 357-379, 2019.

[22] Y. Song, F. Wang, and X. Chen, "An improved genetic algorithm for numerical function optimization," Applied Intelligence, vol. 49, no. 5, pp. 1880-1902, 2019. 